Gülşen Altınkanat Gelmez (1)
Elvan Sayın (1)

Ufuk Hasdemir (1)

Güner Söyletir (1)

\title{
Evaluation of Diagnostics Colistin MIC-Strip Test for Colistin Susceptibility Testing
}

öz

Günümüzde çoklu ilaç direncine sahip Gram negatif mikroorganizmaların neden olduğu enfeksiyonların tedavisinde kullanılacak antimikrobiyallerin kısıtlı olması nedeniyle kolistin gibi eski antibiyotikler sıklıkla tercih edilmeye başlanmıştır. Ancak, kolistinin katyonik yapısı nedeniyle rutin laboratuvarda sıklıkla kullanılan antibiyotik duyarlılk testlerinde (disk difüzyon, gradient test, otomatize sistemler) birtakım sorunlar yaşanmaktadır. Bu nedenle European Committee on Antimicrobial Susceptibility Testing (EUCAST) ve Clinical and Laboratory Standards Institute (CLSI) tarafından kolistin duyarlıığını saptamak için sadece sIVI mikrodilüsyon testi önerilmektedir. Ancak sIVI mikrodilüsyon testlerinin zaman alıcı ve zahmetli olması nedeniyle rutin laboratuvarlarında hızlı ve güvenilir kolistin duyarlılığı sonucu sağlayabilen testlere ihtiyaç duyulmaktadır. Bu çalışmada, Klebsiella pneumoniae ve Acinetobacter baumannii kökenlerinde kolistin duyarlıığının saptanmasında ticari olarak hazır olarak üretilen Diagnostics MIC-COL (Diagnostics I.n.C., Galanta, Slovakya) testinin performansının değerlendirilmesi amaçlanmıştır. Rutin laboratuvarımızda 2016-2019 yılları arasında çeşitli klinik örneklerden izole edilen K.pneumoniae $(n=22)$ ve A.baumannii $(n=28)$ kökenleri çalıșmaya dahil edilmistir. Kökenlerin kolistin minimum inhibitör konsantrasyonları (MiK) hem referans yöntem olan sIVI mikrodilüsyon yöntemi ile hem de ticari olarak üretilen Diagnostics MIC-COL testi ile çalışılmıştır. Elde edilen sonuçlar karşılaştııılarak testin temel uyum, kategorik uyum, büyük hata ve çok büyük hata oranları hesaplanmısstır. SIVı mikrodilüsyon yöntemi ile karșılaștırıldığında Diagnostics MIC-COL testinin temel uyumu \% 84, kategorik uyumu \% 98, büyük hata oranı \% 3,8 olarak tespit edilirken çok büyük hata tespit edilmemiştir. Rutin laboratuvarlarda hızlı ve güvenilir kolistin duyarlıığının tespit edilerek tedavinin yönlendirilmesi oldukça önemlidir. Calısmamızda kullanılan ticari test kullanımı kolay ve zaman alıcı olmayan bir testtir. Ayrıca strip şeklinde olması sayesinde her izolat ayrı çalısılabilmektedir. Büyük hata oranının beklenilen değerlerin üzerinde olması nedeniyle daha fazla sayıda ve farklı direnç düzeylerine sahip kökenlerle yapılacak ileri çalıșmalarla bu oranların yeniden değerlendirilmesi faydalı olacaktır.

Anahtar kelimeler: A.baumannii, diagnostics MIC-COL-strip, kolistin duyarlılı̆ı, K.pneumoniae

\section{ABSTRACT}

Due to the limited number of antimicrobials to be used in the treatment of infections caused by Gram-negative microorganisms with multi-drug resistance recently, old antibiotics such as colistin have started to be preferred frequently. However, some problems are encountered in antibiotic susceptibility tests (disk diffusion, gradient test, automated systems) which are frequently used in the routine laboratory due to the cationic nature of colistin. For this reason, only the broth microdilution test is recommended by European Committee on Antimicrobial Susceptibility Testing (EUCAST) and Clinical and Laboratory Standards Institute (CLSI) for the detection of colistin susceptibility. Since broth microdilution tests are time consuming and inconvenient, tests that can provide fast and reliable colistin susceptibility result is needed in routine laboratories. In this study, it was aimed to evaluate the performance of the commercially produced Diagnostics MIC-COL test (Diagnostics I.n.c, Galanta, Slovakia) for the detection of colistin susceptibility in Klebsiella pneumoniae and Acinetobacter baumannii strains. The strains of K.pneumoniae $(n=22)$ and A.baumannii $(n=28)$ isolated from various clinical specimens between 2016 and 2019 in our routine laboratory were included in the study. Colistin minimum inhibitory concentrations (MIC) of the strains were studied with both the reference broth microdilution method and the commercially produced Diagnostics Colistin MIC-COL test. The essential agreement, categorical agreement, major error, and very major error rates of the test were calculated by comparing the obtained results. The essential agreement of the Diagnostics Colistin MIC-Strip test was determined as $84 \%$, categorical agreement as $98 \%$, and major error rate as $3.8 \%$, while no very major error was detected. it is very important to quide antimicrobial treatment with rapid and reliable detection of colistin susceptibility. The commercial test used in our study is easy to use and not time-consuming. Also, due to its strip from, each isolate can be studied separately. Because of the major error rate being above the expected values, it will be useful to re-evaluate these rates with further studies to be conducted with a larger number of strains with different resistance levels.

Keywords: A.baumannii, colistin susceptibility, diagnostics MIC-COL-strip, K.pneumoniae

Atıf/Cite as: Altınkanat Gelmez G, Sayın E., Hasdemir U, Söyletir G. Kolistin duyarlıık testi için diagnostics colistin mic-strip testinin değerlendirilmesi. ANKEM Derg. 2021;35(1):913.

Gülșen Altnkanat Gelmez

Marmara Üniversitesi Tıp Fakültesi, Tibbi Mikrobiyoloji Anabilim Dalı, İstanbul, Türkiye

gulsenaltinkanat@yahoo.com ORCID: 0000-0003-0274-628X

E. Sayın 0000-0002-1320-1704

U. Hasdemir 0000-0002-1606-0804 G. Söyletir 000-0001-5695731X

Marmara Üniversitesi Tıp Fakültesi, Tıbbi Mikrobiyoloji Anabilim Dalı, İstanbul, Türkiye

*5. Ulusal Klinik Mikrobiyoloji Kongresi'nde poster olarak sunulmustur. Poster No: 44 (28 Ekim-1 Kasım 2019, Izmir) 


\section{Giriş}

Son yılda Acinetobacter spp., Pseudomonas spp. ve karbapenemaz üreten Enterobacterales gibi çok ilaca dirençli Gram negatif bakterilerin neden olduğu enfeksiyonlar tüm dünyada endişe verici düzeyde artmaktadır. Bu enfeksiyonlarda kullanılacak tedavi seçenekleri de oldukça sınırlıdır. Illk olarak 1949'da Paenibacillus polymyxa'dan izole edilen kolistin, bir heptapeptid halkası, bir ekzosiklik zincir ve Gram negatif lipopolisakkarit membranı ile etkileşime giren pozitif yüklü bir yağ asiti kuyruğundan oluşan katyonik bir polipeptitdir. Klinik kullanıma 1959'da girmiş ancak nefrotoksik ve nörotoksik etkileri ve doz optimizasyonundaki problemler nedeniyle 1980'lerde kullanımları sınırlandırılmıştır. Yapılan bazı çalışmalarda kolistin sülfatın intravenöz formunun daha güvenilir olduğu gösterildikten sonra çok ilaca dirençli Gram negatif bakterilerin neden olduğu enfeksiyonlarda kullanımı tekrar gündeme gelmiştir. Kolistinin hızlı bakterisidal etkisi, geniş spektrumlu aktiviteye sahip olması ve yeni geliştirilen antibiyotiklerin sayısının azalması gibi nedenlerden ötürü 1990'lardan itibaren klinisyenler tarafından tekrar tercih edilmeye başlanmıştır ${ }^{(8)}$.

Son yıllarda kolistin kullanımındaki artış beraberinde direnç oranlarının da artışına sebep olmuştur. Uygun tedavi protokolünün belirlenmesi için hızlı, doğru ve güvenilir in vitro antibiyotik duyarlılık testlerinin yapılması oldukça önemlidir. Kolistinin katyonik yapısı, büyük molekül ağırlığı nedeniyle agarda zayıf difüzyonu, ilaç kompozisyonlarındaki değişimler ve heterodirenç gibi özellikleri nedeniyle rutin laboratuvarda sıklıkla kullanılan antibiyotik duyarlıık testlerinde (disk difüzyon, gradient test, otomatize sistemler) birtakım sorunlar yaşanmaktadır ${ }^{(19)}$. Yapılan birçok çalışmada bu yöntemler ile elde edilen sonuçlarda kabul edilemeyecek düzeyde çok büyük hata tespit edilmiştir ${ }^{(9,17)}$. Clinical and Laboratory Standards Institute (CLSI) - European Committee on Antimicrobial Susceptibility Testing (EUCAST) Polimiksin Çalışma Grubu tarafından 2016 yıında kolistin duyarlılığını saptamak için polisorbat-80 gibi katkı maddeleri olmaksızın polistren plaklarda yapılan SIVı mikrodilüsyon yöntemi referans yöntem olarak belirlenmiştir ${ }^{(6)}$. Ancak sıvı mikrodilüsyon testlerinin zaman alıcı ve zahmetli olması nedeniyle günlük iş akışı içerisinde rutin mikrobiyoloji laboratuvarlarında uygulanması oldukça zordur. Bu nedenle hızlı, güvenilir, tekrarlanabilirliği yüksek ve kullanıcı dostu antibiyotik duyarlıık testlerinin geliştirilmesine intiyaç vardır. Bu amaçla geliştirilen Diagnostics MICCOL (Diagnostics I.n.c, Galanta, Slovakya) testi, liyofi- lize 7 farklı konsantrasyonda (0,25-16 mg/L) kolistin içeren tekli polistren stripler halinde kullanıma hazır bir sIVı mikrodilüsyon kitidir.

Çalışmamızda, Klebsiella pneumoniae ve Acinetobacter baumannii kökenlerinde kolistin duyarlılığının saptanmasında ticari olarak hazır olarak üretilen Diagnostics MIC-COL (Diagnostics I.n.c, Galanta, Slovakya) testinin performansının değerlendirilmesi amaçlanmıştır.

\section{GEREÇ VE YÖNTEM}

Bakterilerin seçimi: 2016-2019 yılları arasında Marmara Üniversitesi Hastanesinde servis ve yoğun bakım ünitelerinde yatmakta olan hastalardan alınıp laboratuvarımıza gönderilen çeşitli klinik örneklerden (apse, bronkoalveolar lavaj, balgam, kan, derin trakeal aspirat, idrar, yara) etken olarak izole edilen Klebsiella pneumoniae ve Acinetobacter baumannii kökenleri incelenmiştir. Kökenlerin tür düzeyinde tanımlamaları matriks aracılı lazer dezorpsiyon iyonizasyon-uçuş zamanlı-kütle spektrometresi (MALDITOF-MS) VITEK-MS (bioMérieux, Marcy-l'Étoile, Fransa) kullanılarak yapılmıştr. Rutin antibiyotik duyarlılıkları K.pneumoniae kökenleri için VITEK Compact (bioMérieux, Marcy-l'Étoile, Fransa) otomatize sistemi ile, A.baumannii kökenlerinin ise disk difüzyon yöntemi ile yapılmıştır. Rutin antibiyotik duyarlılık profillerine bakılarak çok ilaca dirençli olduğu tespit edilen 22 K.pneumoniae ve 28 A.baumannii kökeni kolistin duyarlılığının belirlenmesi için çalışma kapsamına alınmıştır.

Antibiyotik duyarlılık testi: Tüm kökenlerin kolistin minimum inhibitör konsantrasyonu (MiK) değerleri EUCAST önerileri doğrultusunda International Organisation for Standardization (ISO) Standart 20776-1'e uygun olarak sıvı mikrodilüsyon yöntemi ile belirlenmiştir ${ }^{(7)}$. Mikrodilüsyon plaklarında aktif madde olan kolistin sülfatın (Sigma-Aldrich, St. Louis, MO, A.B.D) seri dilüsyonları (0,25- $16 \mathrm{mg} / \mathrm{L})$ katyon eklenmiş Müeller Hinton sıvı besiyeri (Becton Dickinson, A.B.D) kullanılarak hazırlanmıştır. Tüm kökenlerden hazırlanan 0,5 Mc Farland standart bulanıklığı son bakteri konsantrasyonu $5 \times 10^{5} \mathrm{cfu} / \mathrm{ml}$ olacak şekilde mikrodilüsyon plaklarına eklenmiş ve 18-20 saat $35^{\circ} \mathrm{C}^{\prime}$ de inkübe edilmiştir. Ayrıca, aynı bakteri inokülümü kullanılarak eş zamanlı olarak 0,25-16 mg/L liyofilize kolistin sülfat konsantrasyonları içeren ticari Diagnostics MIC-COL (Diagnostics I.n.c, Galanta, Slovakya) üreticinin önerileri doğrultusunda çalışılmıştır. Sonuçlar EUCAST'ın kolistin sınır 
değerlerine ( $\leq 2 \mathrm{mg} / \mathrm{L}$ duyarli; >2 mg/L dirençli) göre yorumlanmıştır. Her iki yöntem için de kontrol köken olarak Escherichia coli ATCC 25922 ve mcr-1 pozitif E.coli NCTC 13846 kullanılmıştır.

Sonuçların değerlendirilmesi: Temel uyum (TU) referans sIVı mikrodilüsyon testi ile ticari yöntem ile elde edilen antibiyotik MiK değerlerinde \pm 1 dilüsyon fark olması, kategorik uyum (KU) ise test edilen kökenin EUCAST kriterlerine göre yorumlanan duyarlılık sonuçlarının (duyarlı, dirençli) her iki yöntem arasındaki uyumu olarak tanımlanmıştır. Büyük hata $(\mathrm{BH})$ referans sıvı mikrodilüsyon yöntemi ile duyarı bulunan bir kökenin ticari yöntem ile dirençli bulunması, çok büyük hata (ÇBH) ise referans sıvı mikrodilüsyon yöntemi ile dirençli olan bir kökenin ticari yöntem ile duyarlı bulunması olarak tanımlanmıştır. ISO tarafından belirlenen kriterlere göre kabul edilebilir performans TU ve KU için $\geq \% 90$, ÇBH ve $\mathrm{BH}^{\prime}$ ler için $\leq \% 3$ olarak belirlenmiştir ${ }^{(11)}$. Kohen'in kappa ( $\left.\boldsymbol{\kappa}\right)$ katsayısI, yöntemler arasındaki uyum derecesini göstermek için hesaplanmıştır. $\boldsymbol{\kappa}>0,75$ ise çok iyi uyum; $\boldsymbol{\kappa}=$ $0,4-0,75$ ise orta-iyi uyum ve $\boldsymbol{\kappa}<0,4$, zayıf uyum şeklinde yorumlanmıştır.

\section{BULGULAR}

Referans sıvı mikrodilüsyon yöntemi ile çalışmaya alınan K.pneumoniae kökenlerinin 9'u (\% 40,9), A.baumannii kökenlerinin 17'si (\% 67) kolistine duyarlı bulunmuştur.

A.baumannii kökenlerinde referans SIVI mikrodilüsyon yöntemi ile Diagnostics MIC-COL testi arasındaki temel uyum $\% 82,1$, kategorik uyum ise \% 100 iken K.pneumoniae kökenlerinde temel uyum \% 86,3 , kategorik uyum ise \% 95,4 olarak saptanmıştır. Bir K.pneumoniae kökeninin kolistin MiK değeri sıvı mikrodilüsyon yöntemi ile $2 \mathrm{mg} / \mathrm{L}$ (duyarlı) iken Diagnostics MIC-COL testi ile $8 \mathrm{mg} / \mathrm{L}$ (dirençli) olarak belirlenmiştir. A.baumannii kökenlerinde büyük hata ve çok büyük hata gözlemlenmemiştir. Tüm kökenler birlikte değerlendirildiğinde sıvı mikrodilüsyon yöntemi ile Diagnostics MIC-COL testi arasındaki temel uyum, kategorik uyum, büyük hata ve çok büyük hata oranları sırasıyla \% 84, \% 98, \% 3,8 ve \% 0'dır (Tablo). Kappa istatistiği ile yöntemler arasında çok iyi düzeyde uyum bulunmuştur ( $\boldsymbol{\kappa}=0.96)$.

\section{TARTIŞMA}

Antibiyotik direnci, halk sağlığını tehdit eden önemli bir sorundur. Tüm dünyada çok ilaca dirençli
(MDR) bakterilerin neden olduğu enfeksiyonlardaki artış endişe verici düzeydedir. Tedavide kullanılacak antimikrobiyaller her geçen gün azalmakta ve yeni ilaç üretimi neredeyse yok denecek kadar azdır.

Tablo. Klebsiella pneumoniae $(\mathrm{n}=\mathbf{2 2})$ ve Acinetobacter baumannii $(n=28)$ için Diagnostics MIC-COL testi ve referans sıvı mikrodilüsyon yöntemiyle elde edilen kolistin MiK değerlerinin karşılaştırılması.

\begin{tabular}{|c|c|c|c|c|c|c|c|c|c|}
\hline & \multicolumn{9}{|c|}{ Kolistin Referans Yöntem Мік (mg/L) } \\
\hline & & 0,25 & 0,5 & 1 & 2 & 4 & 8 & 16 & $>16$ \\
\hline \multirow{8}{*}{$\begin{array}{l}\text { Diagnostics } \\
\text { MIC -COL } \\
\text { (mg/L) }\end{array}$} & 0,25 & & 1 & 2 & & & & & \\
\hline & 0,5 & & 3 & 9 & 1 & & & & \\
\hline & 1 & & 2 & 2 & & & & & \\
\hline & 2 & & 1 & 2 & 2 & & & & \\
\hline & 4 & & & & & 1 & & & \\
\hline & 8 & & & & 1 & & 2 & 3 & 1 \\
\hline & 16 & & & & & & 4 & 5 & 3 \\
\hline & $>16$ & & & & & & 2 & 1 & 2 \\
\hline
\end{tabular}

Kolistin, karbapenem dirençli Gram negatif bakterilere karşı sınılı tedavi seçenekleri nedeniyle son zamanlarda önemli bir antibiyotik olarak yeniden gündeme gelmiştir. Yakın zamana kadar kolistin direncinin kromozomal olarak kodlandığı bilinirken, 2015 yılında ilk plazmid aracılı direnç geni olan $\mathrm{mcr}-1$ tanımlanmıştır. Son yıllarda da diğer direnç genleri (mcr-2, mcr-3, mcr-4, mcr-5, mcr-6, mcr-7 ve mcr-8) tespit edilmiştir. Plazmid aracılığıyla transfer edilen bu direnç genlerinin 4-8 mg/L gibi düşük düzey kolistin direncine neden olduğu belirlenmiştir ${ }^{(1,8,13)}$. European Centre for Disease Prevention and Control (ECDC), Haziran 2016'da plazmid aracılı kolistin direncinin yayılmasını kontrol etmek için bir rapor hazırlamıştır ${ }^{(5)}$. Bu raporda sürveyans ve antimikrobiyal yönetim uygulamalarına yönelik yapılması gereken eylem planları ele alınmıştır. Bu planlar arasında kolistin MiK değerini doğru tespit edebilecek laboratuvar yöntemlerinin belirlenmesi ve direnç genlerinin moleküler olarak tespit edilmesi yer almaktadır. Hem başarılı antibakteriyel tedavi sağlamak hem de kolistinin olası toksik etkilerinden korunmak için güvenilir bir yöntem ile MiK değerinin belirlenmesi enfeksiyonun doğru yönetimi için oldukça önemli$\operatorname{dir}^{(2)}$. Ancak, kolistin klinik uygulamalarda sıklıkla tercih edilmeye devam ederken rutin laboratuvarlarda kolistin duyarlılı̆̆ını belirlemek için hangi yöntemlerin kullanılabileceği belirsizliğini korumaktadır.

Birçok laboratuvarda sıklıkla kullanılan antibiyotik duyarlılık yöntemleri disk difüzyon, gradient test ve otomatize sistemlerdir. Disk difüzyon ve gradient test 
yöntemleri özel ekipman gerektirmeyen, düşük maliyetli ve kullanımı kolay testlerdir. Ancak polimiksinler büyük ve katyonik yapılarından dolayı agar yüzeyine yeterli miktarda difüze olamazlar. Bu nedenle disk difüzyon ve gradient test yöntemleri kolistin için güvenilir antibiyotik duyarlılık test kategorisinde yer almamaktadırlar. Kolistin disk difüzyon ve gradient difüzyon testleriyle yapılan çalışmalarda kabul edilemeyecek düzeylerde büyük hata veya çok büyük hata oranları tespit edilmiştir. Duyarlı ve dirençli izolatlar arasında ayırım yapılamamakta ve özellikle düşük düzey direncin saptanmasında yetersiz kalmaktadır$\operatorname{lar}^{(4,12,14,15,17)}$

Otomatize sistemler ise klinik mikrobiyoloji laboratuvarlarında iş yükünü azaltmaları. tekrarlanabilirliklerinin yüksek olması. uzman sistem analizi ile veri yönetimi yapılabilmesi ve daha kısa sürede sonuca ulaşılabilmesi nedeniyle sık kullanılan yöntemlerdir. Ancak her antibiyotik için test edilen konsantrasyon sayısı sınırlıdır ve gerçek bir Mik değeri vermezler. Chew ve ark.'nın ${ }^{(3)}$ yaptıkları çalışmada VITEK 2 ile referans yöntem arasında temel uyum oranı \% 93,4 ve kategorik uyum oranı $\% 88,2$ olmasına rağmen çok büyük hata oranı $\% 36$ olarak tespit edilmiştir. Vourli ve ark. ${ }^{(19)}$ tarafından yapılan çalışmada kolistin duyarlılığının belirlenmesinde kullanılan Phoenix 100 ve VITEK 2 otomatize sistemlerinin çok büyük hata oranları sırasıyla \% 41,4 ve \% 37,9 olarak tespit edilmiştir. Çok büyük hatalar genellikle MiK değeri 1-2 $\mathrm{mg} / \mathrm{L}$ olan izolatlarda tespit edilmiştir. Bu nedenle otomatize sistemde duyarlı olarak saptanan kökenlerin referans yöntem ile doğrulanması gerektiğini vurgulamışlardır ${ }^{(18)}$. Girardello ve ark. ${ }^{(10)}$ yaptıkları çalışmada VITEK 2 ile en iyi performansın MiK değeri $\leq 0,5$ ve $\geq 16 \mathrm{mg} / \mathrm{L}$ olan K.pneumoniae ve E.coli kökenlerinde elde edildiğini ve MiK değeri 1-8 mg/L olarak belirlenen tüm kökenlerin referans yöntem ile doğrulanması gerektiğini belirtmişlerdir.

Birçok laboratuvarın bu yöntemleri sıklıkla laboratuvarda kullandığı göz önüne alındığında, kolistin için bu yöntemlerle hatalı sonuç verme intimali oldukça yüksektir. Bu da klinisyenlerin uygunsuz kolistin kullanmasına yol açacak bir durumdur. Bu nedenle CLSI-EUCAST Polimiksin Çalışma Grubu tarafından kolistin duyarlılığının belirlenmesi için sadece SIVı mikrodilüsyon yöntemi önerilmektedir ${ }^{(6)}$. SIVI mikrodilüsyon yöntemi zahmetli, zaman alıcı ve özellikle dilüsyonların hazırlanması açısından deneyim gerektiren bir yöntemdir. Bu nedenle rutin mikrobiyoloji laboratuvarlarında yapılması oldukça zordur. Bu açıdan klinik mikrobiyoloji laboratuvarları için yeni yöntemlerin geliştirilmesi zorunludur. Ticari antibiyotik duyarlılık test panelleri (Sensititre, Micronaut, UMIC vb) ümit vadeden alternatif yöntemler olarak karşımıza çıkmaktadır. Bu yöntemlerin performansını değerlendiren çalışmaların mevcut verileri ışı̆̆ında rutin laboratuvarda kolistin duyarlıı̆ı̆ını saptamada kullanılabilecek güvenilir yöntemler olarak gözükmektedirler. Matuschek ve ark. ${ }^{(16)}$ çalışmalarında beş ticari ürünün (Sensititre, Micronaut-S, Micronaut MIC-Strip, SensiTest ve UMIC) referans SIVI mikrodilüsyon yöntemi ile temel uyum oranını $\% 82-\% 99$, kategorik uyum oranını $\% 89-\% 95$, büyük hata oranını \% 3-\% 7 ve çok büyük hata oranını \%3 olarak bildirmişlerdir. Çalışmamızda kullanılan Diagnostics MIC-COL testinin hazırlık prosedürü kolaydır ve ek bir ekipman gerektirmemektedir. Değerlendirilmesi basit ve hızlı bir testtir. Testin strip şeklinde olması her hasta örneğinin ayrı ayrı çalışıımasına imkan sağlaması açısından oldukça önemlidir. Testin referans yöntem ile kategorik uyum oranı yüksek olup, çok büyük hata gözlemlenmemiştir. Büyük hata yüzdesi $(\% 3,8)$ tavsiye edilen değerlerin $(\mathrm{BH}<\% 3)$ üzerinde kalmaktadır. Bu durum çalışmamızda kullanılan izolat sayısının az olması ile ilişkili olabilir. Bu nedenle daha fazla sayıda ve farklı direnç düzeylerine sahip kökenlerle yapılacak ileri çalışmalarla bu oranların yeniden değerlendirilmesi faydalı olacaktır.

Ticari dilüsyon panelleri yoğun örnek kapasitesine ve direnç oranlarına sahip rutin laboratuvarlar için kullanışlı olabilir. Uygun tedavi kararının verilebilmesi için rutin mikrobiyoloji laboratuvarlarına bu ürünlerin entegre olmaları oldukça önemlidir. Bu sayede uygunsuz kolistin kullanımının önüne geçilerek direnç gelişimi sınırlandııılabilir.

Çıkar Çatışması: Yazarlar tarafından herhangi bir çıkar çatışması bildirilmemiştir.

Conflict of Interest: No conflict of interest was declared by the authors.

\section{KAYNAKLAR}

1. Baron S, Hadjadj L, Rolain JM, Olaitan AO. Molecular mechanisms of polymyxin resistance: knowns and unknowns. Int J Antimicrob Ag. 2016;48(6):583-91. https://doi.org/10.1016/j.ijantimicag.2016.06.023

2. Caniaux I, van Belkum A, Zambardi G, Poirel L, Gros MF. MCR: modern colistin resistance. Eur J Clin Microbiol Infect Dis. 2017;36(3):415-20. https://doi.org/10.1007/s10096-016-2846-y

3. Chew KL, La MV, Lin RTP, Teo JWP. Colistin and polymyxin b susceptibility testing for carbapenemresistant and mcr-positive Enterobacteriaceae: comparison of Sensititre, MicroScan, Vitek 2, and Etest with broth microdilution. Journal of Clinical 
Microbiology. 2017;55(9):2609-16.

https://doi.org/10.1128/JCM.00268-17

4. Dafopoulou K, Zarkotou O, Dimitroulia E, et al. Comparative evaluation of colistin susceptibility testing methods among carbapenem-nonsusceptible Klebsiella pneumoniae and Acinetobacter baumannii clinical isolates. Antimicrob Agents Chemother 2015;59(8):4625-30.

https://doi.org/10.1128/AAC.00868-15

5. ECDC. Plasmid-mediated colistin resistance in Enterobacteriace ae. 2016. https://ecdc.europa.eu/ sites/portal/files/media/en/publications/Publications/ enterobacteriaceae-risk-assessment-diseases-causedby-antimicrobial-resistant-microorganisms-europejune-2016.pdf.

6. European Committee on Antimicrobial Susceptibility Testing. Recommendations for MIC determination of colistin (polymyxin E) as recommended by the joint CLSI-EUCAST Polymyxin Breakpoints Working Group. (2016).

7. European Committee on Antimicrobial Susceptibility Testing. 2019. Breakpoint tables for interpretation of MICs and zone diameters, version 9.0.(2019).

8. Ezadi F, Ardebili A, Mirnejad R. Antimicrobial susceptibility testing for polymyxins: challenges, issues, and recommendations. J Clin Microbiol. 2019;57(4). https://doi.org/10.1128/JCM.01390-18

9. Galani I, Kontopidou F, Souli M, et al. Colistin susceptibility testing by Etest and disk diffusion methods. Int J Antimicrob Agents. 2008;31(5):434-9. https://doi.org/10.1016/j.ijantimicag.2008.01.011

10. Girardello R, Cury AP, Franco MRG, et al. Colistin susceptibility testing and Vitek-2 (TM): is it really useless? Diagn Microbiol Infect Dis. 2018;91(4):30911.

https://doi.org/10.1016/j.diagmicrobio.2018.03.019

11. International Organization for Standardization (ISO). Clinical Laboratory Testing and In Vitro Diagnostic Test Systems. Susceptibility Testing of Infectious Agents and Evaluation of Performance of Antimicrobial Susceptibility Test Devices. Part 2: Evaluation of Performance of Antimicrobial Susceptibility Test Devices. International Standard ISO 20776-2:2007. Geneva, Switzerland. (2007).

12. Lee SY, Shin JH, Lee K, et al. Comparison of the Vitek 2, MicroScan, and etest methods with the agar dilution method in assessing colistin susceptibility of bloodstream isolates of Acinetobacter species from a Korean University Hospital. J Clin Microbiol. 2013;51(6):1924-6. https://doi.org/10.1128/JCM.00427-13

13. Liu YY, Wang Y, Walsh TR, et al. Emergence of plasmidmediated colistin resistance mechanism MCR-1 in animals and human beings in China: a microbiological and molecular biological study. Lancet Infect Dis. 2016;16(2):161-8. https://doi.org/10.1016/S1473-3099(15)00424-7

14. Lo-Ten-Foe JR, de Smet AMGA, Diederen BMW, Kluytmans JAJW, van Keulen PHJ. Comparative evaluation of the VITEK 2, disk diffusion, etest, broth microdilution, and agar dilution susceptibility testing methods for colistin in clinical isolates, including heteroresistant Enterobacter cloacae and Acinetobacter baumannii strains. Antimicrob Agents Chemother. 2007;51(10):3726-30. https://doi.org/10.1128/AAC.01406-06

15. Maalej SM, Meziou MR, Rhimi FM, Hammami A. Comparison of disc diffusion, Etest and agar dilution for susceptibility testing of colistin against Enterobacteriaceae. Lett Appl Microbiol. 2011;53(5):546-51. https://doi.org/10.1111/j.1472-765X.2011.03145.x

16. Matuschek E, Ahman J, Webster C, Kahlmeter G. Antimicrobial susceptibility testing of colistin evaluation of seven commercial MIC products against standard broth microdilution for Escherichia coli, Klebsiella pneumoniae, Pseudomonas aeruginosa, and Acinetobacterspp. Clin Microbiol Infec. 2018;24(8):86570. https://doi.org/10.1016/j.cmi.2017.11.020

17. Tan TY, Lily SYN. Comparison of three standardized disc susceptibility testing methods for colistin. J Antimicrob Chemother. 2006;58(4):864-7. https://doi.org/10.1093/jac/dkl330

18. Vasoo S. Susceptibility Testing for the polymyxins: two steps back, three steps forward? J Clin Microbiol. 2017;55(9):2573-82. https://doi.org/10.1128/JCM.00888-17

19. Vourli S, Dafopoulou K, Vrioni G, Tsakris A, Pournaras S. Evaluation of two automated systems for colistin susceptibility testing of carbapenem-resistant Acinetobacter baumannii clinical isolates. J Antimicrob Chemother. 2017;72(9):2528-30. 